ORIGINAL ARTICLE

\title{
Uterine Leiomyoma and Pregnancy Outcome: An Experience at Tertiary Care Setup
}

\author{
FARHA NAZ CHOHAN ${ }^{1}$, SHAISTA MEMON ${ }^{2}$, SABREENA ABBAS ${ }^{3}$, SYEDA HIRA ALI SHAH ${ }^{4}$, ALIYA SHAMIM ${ }^{5}$, AFROZ \\ ${ }^{1}$ Registrar, Civil Hospital, Hyderabad \\ ${ }^{2}$ WMO, Sir CJ psychiatry Hospital Hyderabad \\ ${ }^{3}$ Assistant Professor, Gynae and OBS, LUMHS Jamshoro \\ ${ }^{4,5}$ WMO Shah Bhittai Hospital Hyderabad ${ }^{6}$ Sindh govt. Hospital Paretabad Correspondence to: Dr. Farha Naz Chohan, \\ E-mail: farhanaz.chohan@yahoo.com
}

\begin{abstract}
Objective: To determine the impact of leiomyoma in pregnant women a tertiary care set up in Hyderabad.

Methods: This prospective observational study conducted at OPD of Gynecology unit-III, Liaquat University of Medical and Health Science Hyderabad, from June 2018 to December 2018. A total of 18,402 pregnant women of age 20-45 years were attended, out of which 195 had leiomyoma and they were asked to take part in study. Data regarding demographic characteristics including complications during pregnancy, and indications of caesarean section was collected via study proforma.

Results: Total 186 out of 195 females were studied, their mean age was $31.23 \pm 3.12$ years, average gestational age was $33.12 \pm 3.15$ weeks and average size of Leiomyoma was $3.12 \pm 2.15 \mathrm{~cm}$. The most common complications were PPHamong $28.49 \%$ of cases, blood transfusion was required in $39.25 \%$ of the cases, miscarriage occurred in $6.45 \%$ of the cases, cord prolapse was seen in $24.3 \%$ cases, placental abruption in $5.91 \%$ cases, placenta previa in $11.32 \%$ cases and retained placenta was observed among $1.61 \%$ of the cases. Preterm labour occurred in $5.38 \%$ of the cases and IUGR was seen in $10.22 \%$ of the cases. Out of all cases, 10 females underwent preterm delivery, while 12 underwent fetus delivery before 24 weeks (miscarriage). Among all term pregnancies, $78.66 \%$ underwent C-Section due to failure in progress, cord prolapsed, fibroid in lower segment, breech presentation and low-lying placenta.

Conclusion: Fibroid complicates pregnancy itself and also the outcome. Rural area dwelling women are at more risk, which include increase in caesarean section and a multifold increased risk of PPH and associated hysterectomy in these cases.

Keywords: Leiomyoma, Uterine Fibroids, Pregnancy, complications.
\end{abstract}

\section{INTRODUCTION}

Leiomyomata or leiomyoma commonly known as fibroid is the most common benign tumour of the uterus. One of every third woman of age 35-65 years may have several fibroids in her uterus, of different sizes, types and location ${ }^{1,2}$. They commonly affect pregnancies, however about $50 \%$ of cases remain undiagnosed because of being asymptomatic until detected on routine ultrasound imaging in antenatal check-ups $^{3}$. Fibroids may or may not interfere with pregnancy; usually $35 \%$ of fibroids increase in size in the first trimester under influence ofhormones ${ }^{4,5}$. They become soft and the subserous types arepalpable and may often be mistaken for fetal parts. Clinical examination during pregnancy can detect $42 \%$ of fibroids only when they are $>5 \mathrm{~cm}$. Ultrasound is the gold standard for mapping the precise size and location of fibroids, while MRI is still more diagnostic, but its use is limited due to higher $\operatorname{cost}^{6}$. The number, size, location, and relation of fibroids to placental implantation are significantfactors to determine the effect of fibroid in pregnancy. Retroplacental fibroids are associated with a higher incidence of miscarriage, preterm labour, placental abruption, and postpartum haemorrhage ${ }^{7,8}$. Fibroids are usually asymptomatic during pregnancy; but may cause pressure symptoms, pain, red or corneous degeneration leading to fibroid ischemia and infarction. Usually; fibroids in pregnancy go uneventful however; may be associated with an increased risk of spontaneous miscarriage, preterm labour, intrauterine growth restriction. Therefore; the fibroid in pregnancy must be carefully handled $d^{9,10}$. Management of fibroid includes CS especially when the fibroid obstructs the birth canal due to its position, like cervical and anterior isthmic fibroids. Fibroids of the uterus should not be observed as thecontraindication for the trial of labour, unless C-section is planned for the obstetric indications as fetal distress, cephalo-pelvic disproportion, malpresentation, prolonged labour, dysfunctional labour, active genital herpes, previous C-section or a huge size fibroid situated close to placenta ${ }^{11}$. The most common postpartum complication of fibroids is $\mathrm{PPH}$, which may extend to emergency hysterectomy ${ }^{12,13}$.

The current study aims to share the experience of a tertiary care set up, which receives great proportion of rural cases of pregnancies with leiomyoma and to assess the impact of leiomyoma on pregnancy outcome including associated complications.

\section{PATIENTS AND METHODS}

The current study was a prospective observational study conducted at OPD of Gynecology unit-III, Liaquat University of Medical and Health Science Hyderabad; from June 2018 to December 2018. Total 18,402 pregnant women of age 20-45 years were attended, out of which 195 had leiomyoma and they were asked to take part in study using consecutive sampling technique. Study was approved from ethical committee of the institute. A written informed consent was taken from all participating women. Exclusion was made on the basis of previous history of hysterectomy/ Myomectomy, smokers/ alcohol users, history of hypertension in first degree relatives, chronic 
diseases like hypertension, IHD or diabetes.

Diagnosis was made on the basis of clinical examination and confirmed by having ultrasound through transvaginal ultrasound showing echogenic uniform area of size measuring 1-10 $\mathrm{cm}$. Data regarding age of mothers, measurement of fibroid, parity, labour and delivery, mode of delivery, complications during pregnancy and indications of C-section were noted. Outcomes included outcome of pregnancy and associated complication due to the fibroid. Data entry and analysis was done using SPSS version 19. Mean and standard deviation was calculated for age, gestational age and size of leiomyoma. Frequency and percentage were computed for categorical variables like residence, complications during pregnancy, labour and delivery, neonatal outcome, mode of delivery and indications of $\mathrm{C}$-section.

\section{RESULTS}

Total 186 females were studied, their mean age was $31.23+3.12$ years, average gestational age was $33.12+3.15$ weeks and average size of Leiomyoma was $3.12 \pm 2.15 \mathrm{~cm}$.
Nearly half of the women belonged to rural areas. Most of the females $(68.28 \%)$ were multipara, while $31.72 \%$ were primipara.Table.1

The most common complications were $\mathrm{PPH}$ among $28.49 \%$ cases, blood transfusion was required in $39.25 \%$ of the cases, miscarriage occurred in $6.45 \%$ of the cases, cord prolapse was in $24.3 \%$ cases, placental abruption was in $5.91 \%$ cases, placenta previa was in $11.32 \%$ cases and retained placenta was observed among $1.61 \%$ of the cases. Breech presentation was seen in $17.83 \%$ cases and $9.14 \%$ cases underwent abdominal hysterectomy. Preterm labour occurred in $5.38 \%$ cases and IUGR was seen in $10.22 \%$ of the cases. Table. 1

Out of all, 164 females continued their pregnancy up toterm and 10 had preterm delivery, while 12 had fetus delivery before 24 weeks (miscarriage). Among all term pregnancies, $21.34 \%$ females underwent vaginal delivery, while $78.66 \%$ underwent $\mathrm{C}$-section due to failure in progress, cord prolapsed, fibroid in lower segment, breech presentation and low-lying placenta as showed in table.1

Table-1: Descriptive statistics of demographic and pregnancy outcome characteristics $n=186$

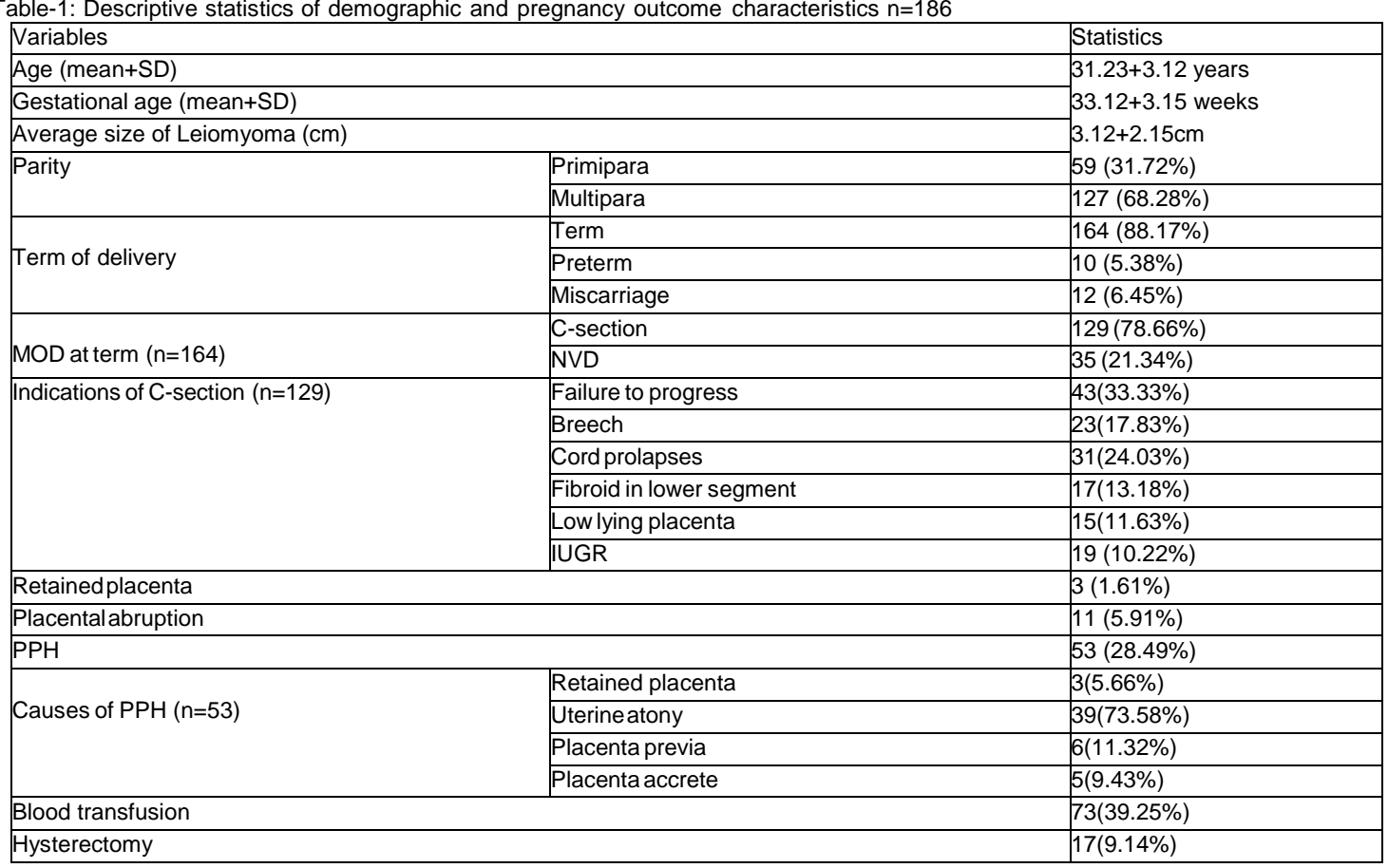

\section{DISCUSSION}

Presence of fibroid increases the risks for materno-fetal health and putting pregnancy prone to complications and adverse outcomes. The current study provides account of a tertiary care set up receiving equal proportion of maternity cases from urban as well as rural areas. We also come across important clinical concern since fibroids are commonly detected in women of reproductive age.

Fibroid in pregnancy is associated with adverse pregnancy events, ${ }^{9,10}$ which were observed in current study, with overall $1.01 \%$ incidence of fibroid pregnancy, which is in concordance with the previously documented studies $(0.74 \%$ to $1.15 \%){ }^{3-5,8} \mathrm{~A}$ few studies have reported lower rate, which may be due to difference in operational criteria and diagnostic methods. ${ }^{7,11,14,15}$

Ultrasonography is, however, a gold standard in evaluating the size, site, number and relationshipof fibroid to placenta. Pakistan is a resource constrained country, where antenatal care and maternity facilities are stillnot fully available at district levels. This leaves the tertiary care hospitals with only option to detect and manage such complicated cases in time.

In this study, majority of cases $(90 \%)$ were in age bracket of 26-35 years and mean age at the time of presentation was $23.12 \pm 3.1$ weeks. This is in contrast to the study by Navid S, et al., ${ }^{9}$ who reported fibroids to be more 
frequent at elder age of around 35 years. On the other hand, our finding of fibroids being common in multigravida $(68 \%)$ was similar to the Navid S, et al., ${ }^{9} \&$ Kokab et $\mathrm{al}^{16}$. The current study noted that rural area women presenting with fibroid uterus in pregnancy are more prone to complications and adverse outcomes.

Fibroid becomes the reason of major mechanical hurdle in birth canal, which may be due to malpresentation of the fetus. ${ }^{10,11}$ This becomes a major indication of caesarean section, which may be accompanied by myomectomy, although not always indicated. In current study, there was $>78 \%$ C-section (CS) rate, which is higher than previousstudies i-e; Navid S, et $\mathrm{al}^{9}$ documented $70.3 \%$ C-section (CS) rate.

In the study by Walker et al, $1472.7 \%$ patients delivered by caesarean section ${ }^{17}$. The indications of CS in current study besides obstructed labor, fetal distress, malpresentation (especially breech presentation) also included having multiple fibroids and the woman has completed her family. This approach may be associated with increased maternal and sometime fetal morbidities, thus the procedure should in general be reserved for emergency situation. ${ }^{11,14}$

Incidence of spontaneous pregnancy loss in current study was 6.45 , which is slightly higher than previous data. 8,13 This association will be strong if there are multiple fibroids or the placenta implantation is low lying (Placenta previa, accrete $)^{10,13}$ as noted in the current study. These condition increases the risk of sever maternal and fetal complications like uterine atony, postpartum hemorrhage and neonatal death. However; in current study a vast majority of fetuses completed their term and incidence of preterm was only $5 \%$. More than a quarter (28.49\%) cases developed $\mathrm{PPH}$ and required emergency management including profuse transfusion. More than nine percent of women underwent hysterectomy as a result of these complications. These results are in concordance with earlier evidence ${ }^{18}$.

Fibroids may actually lie in the line of the CS incision, the decision regarding caesarean myomectomy $(\mathrm{CM})$ during $\mathrm{CS}$, should be taken with great care and the incision on the fibroid should be transverse to coincide with the CS incision, so that both the operations can be completed with one wound closure in the uterus. Patient should be counselled in advance.

\section{CONCLUSION}

Fibroid tends to complicate the pregnancy itself and also the outcome. Rural areas women are at more risk of these complications, which include increase in caesarean section rate, especially due to dysfunctional labour and malpresentation. There is a multifold increased risk of $\mathrm{PPH}$ and associated hysterectomy in these cases.

\section{REFERENCES}

1. Kinugasa-Taniguchi $Y$, Ueda $Y$, Hara-Ohyagi $C$, Enomoto $T$, Kanagawa T, Kimura T. Impaired delivery outcomes in pregnancies following myomectomy compared to myomacomplicated pregnancies. J Reprod Med. 2011 Mar-Apr;56(34):142-8.

2. Wise LA, Laughlin-Tommaso SK. Epidemiology of uterine fibroids: from menarche to menopause. Clin Obstet Gynecol. 2016;59:2.

3. Stewart EA, Cookson CL, Gandolfo RA, Schulze-Rath R. Epidemiology of uterine fibroids: a systematic review. BJOG. 2017 Sep;124(10):1501-12.

4. Saleh HS, Mowafy HE, Hameid AAAE, Sherif HE, Mahfouz EM. Does Uterine Fibroid Adversely Affect Obstetric Outcome of Pregnancy? Biomed Res Int. 2018 Mar 26;2018:8367068.

5. Zhao R, Wang X, Zou L, Li G, Chen Y, Li C, Zhang W. Adverse obstetric outcomes in pregnant women with uterine fibroids in China: A multicenter survey involving 112,403 deliveries. PLoS One. 2017 Nov 14;12(11):e0187821.

6. Amjad S, lqbal H, Bacha R, Gilani SA, Uzair M, Malik SS, Fatima M, Farooq SMY. Sonographic association of uterine firoids with infertility among women of childbearing age. Professional Med J 2020; 27(4):711-716.

7. McWilliams MM, Chennathukuzhi VM. Recent Advances in Uterine Fibroid Etiology. Semin Reprod Med. 2017 Mar;35(2):181-9.

8. Ciavattini A, Clemente N, Delli Carpini G, Di Giuseppe J, Giannubilo SR, Tranquilli AL. Number and size of uterine fibroids and obstetric outcomes. J Matern Fetal Neonatal Med. 2015 Mar;28(4):484-8.

9. Navid S, Arshad S, Qurat-ul-Ain, Meo RA. Impact of leiomyoma in pregnancy. J Ayub Med Coll Abbottabad. 2012 Jan-Mar;24(1):90-2. PMID: 23855105.

10. Zaima A, Ash A. Fibroid in pregnancy: characteristics, complications, and management. Postgrad Med J. 2011 Dec;87(1034):819-28.

11. Milazzo GN, Catalano A, Badia V, Mallozzi M, Caserta D. Myoma and myomectomy: Poor evidence concern in pregnancy. J Obstet Gynaecol Res. 2017 Dec;43(12):17891804.

12. Munusamy M, Sheelaa W, Lakshmi V. Clinical presentation and prevalence of uterine fibroids: a 3-year study in 3-decade rural South Indian women. Int J Reprod, Contracept, Obs Gynecol. 2017;6(12):5596-5601.

13. Levast F, Legendre G, Bouet PE, Sentilhes L. Prise en charge des myomes utérins durant la grossesse [Management of uterine myomas during pregnancy]. Gynecol Obstet Fertil. 2016 Jun;44(6):350-4.

14. Kayadibi Y, Ozmen E, Emir H, Emre S, Dervisoglu S, Adaletli Subserosal leiomyoma of uterus mimicking an ovariantumor in adolescent patient. Jpn J Radiol. 2014;32:48-52.

15. Ishtiaq S, Gazder DP, Khan N. Presentation and management of multiple uterine fibroids in an adolescent girl. Pak J Med Dent. 2014;3(2):55-8.

16. Kokab H, Elahi N, Shaheen T. Pregnancy associated with Fibroids: Complications and pregnancy outcome. J Coll Physicians Surg Pak 2002;12:731-4.

17. Walker WJ, McDowell SJ. Pregnancy after uterine artery embolization for leiomyomata: a series of 56 completed pregnancies. Am J Obstet Gynecol 2006;195:1266-71.

18. Shagufta NO, Khalid J. Adenomyosis among sample from hysterectomy due to abnormal uterine bleeding. J Ayub Med Coll Abbottabad. 2013;25(1-2):68-70. 